\title{
Clinical implications with tolvaptan on monitored bioimpedance-defined fluid status in patients with cirrhotic ascites: an observational study
}

Shunsuke Shiba ${ }^{1}$, Po-sung Chu ${ }^{1 *}$, Nobuhiro Nakamoto ${ }^{1}$, Karin Yamataka ${ }^{1}$, Nobuhito Taniki ${ }^{1}$, Keisuke Ojiro ${ }^{1,2}$, Akihiro Yamaguchi ${ }^{1}$, Rei Morikawa', Aya Yoshida', Akihiko Ikura', Hirotoshi Ebinuma ${ }^{1,3}$, Hidetsugu Saito ${ }^{1,4}$ and Takanori Kanai ${ }^{i *}$

\begin{abstract}
Background: Prognostic value or clinical implications of fluid status monitoring in liver cirrhosis are not fully elucidated. Tolvaptan, an orally available, selective vasopressin V2-receptor antagonist approved for hyponatremia in the United States and European Union. It is also used for cirrhotic ascites at a relatively low dose (3.75 mg to 7.5 $\mathrm{mg}$ ) in Japan, exerts its diuretic function by excreting electrolyte-free water. We hypothesized that bioimpedancedefined dynamic changes in fluid status allow prediction of response of V2 antagonism and survival in cirrhotic patients.

Methods: In this prospective observational study, 30 patients with decompensated liver cirrhosis who were unresponsive to conventional diuretics were enrolled. Detailed serial changes of body composition that were assessed by using non-invasive bioimpedance analysis (BIA) devices, along with biochemical studies, were monitored at 5 time points.
\end{abstract}

Results: Sixteen patients were classified as short-term responders (53\%). Rapid and early decrease of BIA-defined intracellular water, as soon as $6 \mathrm{~h}$ after the first dose $\left(\Delta \mid C W_{B I A} \%-6 \mathrm{~h}\right)$, significantly discriminated responders from non-responders ( $A \cup C=0.97, P<0.0001$ ). $\Delta I C W_{B I A} \%-6 \mathrm{~h}$ was highly correlated with the change of BIA-derived phase angle of trunk, e.g. reduced body reactance operated at $50 \mathrm{kHz}$ after $24 \mathrm{~h}$ of the first dose of tolvaptan. Lower baseline blood urea nitrogen and lower serum aldosterone were predictive of a rapid and early decrease of ICW BIA. $_{\text {. }}$ A rapid and early decrease of ICW BIA in response to tolvaptan was also predictive of a better transplant-free survival.

Conclusions: BIA-defined water compartment monitoring may help predict short-term efficacy and survival in decompensated cirrhotic patients treated with tolvaptan.

Keywords: Ascites, Impedance, Liver cirrhosis, Vasopressin antagonism

\footnotetext{
*Correspondence: pschu0928@iCloud.com; takagast@z2.keio.jp

'Division of Gastroenterology and Hepatology, Department of Internal

Medicine, Keio University School of Medicine, 35 Shinanomachi, Shinjuku-ku,

Tokyo 160-8582, Japan

Full list of author information is available at the end of the article
}

C C The Author(s). 2020 Open Access This article is licensed under a Creative Commons Attribution 4.0 International License, which permits use, sharing, adaptation, distribution and reproduction in any medium or format, as long as you give appropriate credit to the original author(s) and the source, provide a link to the Creative Commons licence, and indicate if changes were made. The images or other third party material in this article are included in the article's Creative Commons licence, unless indicated otherwise in a credit line to the material. If material is not included in the article's Creative Commons licence and your intended use is not permitted by statutory regulation or exceeds the permitted use, you will need to obtain permission directly from the copyright holder. To view a copy of this licence, visit http://creativecommons.org/licenses/by/4.0/ The Creative Commons Public Domain Dedication waiver (http://creativecommons.org/publicdomain/zero/1.0/) applies to the data made available in this article, unless otherwise stated in a credit line to the data. 


\section{Background}

Liver cirrhosis, one of the leading health threat worldwide, yields larger years lived with disability (YLDs) globally than either hepatitis or hepatocellular carcinoma (HCC) [1]. Annually, 5 to $10 \%$ of patients with compensated cirrhosis develop ascites [2]. Hospitalization due to refractory ascites is one of the most frequent reasons for health-care cost in liver cirrhosis [3]. An unmet need for the treatment of refractory cirrhotic ascites still exists.

Although with possible reported limitations $[4,5]$, the non-invasiveness of bioimpedance analysis (BIA) has charmed many researchers to survey its possible application in healthy and diseased populations. BIA has been showed to be an adequate tool for evaluation of total body water (TBW) and extracellular water (ECW) in cirrhotic patients with ascites, $[6,7]$ and has been reported to assess body cell mass (BCM) after trans-jugular intrahepatic porto-systemic shunt (TIPS) in liver cirrhosis [8]. Newly developed ascites is a cardinal symptom of acute decompensation of cirrhosis and may occur in the setting of acute-on-chronic liver failure characterized by dysfunction in multiple organ systems, including renal and cardiovascular failure [9]. The pathophysiology of ascites due to liver cirrhosis is thought to be multifactorial. Malnutrition, systemic inflammation, and exaggerated activation of the renin-angiotensin-aldosterone system (RAAS) [10] play roles in the pathogenesis of cirrhotic ascites. These factors are also common pathophysiological features of fluid control in hemodialysis patients due to chronic renal failure. Body composition and fluid status monitoring assessed by non-invasive BIA, especially intracellular water (ICW), have been shown to be of prognostic value in acute decompensated heart failure, [11] acute kidney injury under continuous hemodiafiltration, [12] and patients with chronic renal failure under hemodialysis $[13,14]$. Therefore, BIA has also been shown to be an applicable tool for assessment of ICW, even in patients with possible overhydration or vigorous fluid status changes. However, in decompensated liver cirrhosis, the prognostic value and clinical implications of fluid status monitoring are not fully elucidated.

Tolvaptan, a selective vasopressin 2 (V2) receptor antagonist, has been indicated for treatment of hypervolemic or euvolemic hyponatremia in the US. Its efficacy and safety have been reported for patients with hyponatremia [15, 16]. Tolvaptan inhibits aquaporin (AQP)-2 channel expression in the collecting ducts and increases the excretion of electrolyte-free water by increasing hypoosmolar urine [17]. In 2013, tolvaptan was approved for use in cirrhotic ascites, whether hyponatremic or not, in Japan at low doses (3.75 mg to $7.5 \mathrm{mg}$ per day) as an add-on (to conventional diuretics) approach [18]. Efficacy and safety have been reported in Japanese cirrhotic patients, including cases with Child-Pugh-Turcotte (CPT) grade $\mathrm{C}$ cirrhosis with this low-dose and add-on approach [19, 20]. In a randomized control trial, tolvaptan has been implicated to improve survival of cirrhotic patients with ascites and hyponatremia, especially in cases whose hyponatremia was resolved by tolvaptan [21]. In recent two observational studies, diuretic responders to tolvaptan showed survival benefit [22, 23]. However, there were still conflicting previous reports regarding diuretic efficacy and safety of V2 antagonism used for hyponatremia in cirrhotic patients [24, 25]. Results from pilot studies of heart failure implicate that V2 antagonism not only retracts ECW but also works to decrease ICW, [26] however, research on how electrolyte-free water excretion that is caused by V2 antagonism affects body composition and fluid status in cirrhotic patients is still sparse. Therefore, the accumulation of evidence for detailed monitoring of fluid status may help its adequate application in cirrhotic individuals.

In this observational study, we hypothesized that the use of add-on low-dose tolvaptan for cirrhotic ascites changes BIA-defined fluid volumes in different compartments, which may be a useful marker for the prediction of its short-term efficacy, and thus long-term survival in these patients.

\section{Methods}

\section{Study subjects and study design}

This study is a single arm, clinical practice-based observation study of a prospectively recruited cohort. The aim of this study is to observe how BIA-defined fluid status changes after add-on tolvaptan administration in patients with cirrhotic ascites. The definition of changes in fluid status is by longitudinal comparison the difference of BIA-defined fluid volumes with those at time 0 by expressing into percent of change $(\Delta \%)$ in each study subject. It is note-worthy that the main purpose of this study is to find out the usefulness of fluid status monitoring after V2 antagonism in cirrhotic patients, rather than to prove the usefulness of a V2 antagonist itself, since a previous study [18] has proved this point. The recruitment of this study was conducted between April 2015 and March 2017, and 30 study subjects were enrolled. Subjects that survived without liver transplantation were followed at least for 1 year after the start of tolvaptan. All the enrolled patients were affected by persistent cirrhotic ascites despite treatment with conventional diuretics, including loop diuretics and aldosterone antagonists, which is coherent to the inclusion criteria raised by Sakaida et al. [18] In short, a cirrhotic patient with more than moderate amount of ascites assessed by physical examination and an image study whose body weight is not apparently decreased by a dose increase of conventional diuretics for at least 7 days is considered for inclusion. Therefore, the inclusion criteria are still considered reasonable even though they are not strictly 
coherent to the definition of "refractory" ascites defined by the International Club of Ascites [27]. Exclusion criteria include: (a) any patient suffering from hypernatremia (serum sodium levels exceeding $145 \mathrm{mmol} / \mathrm{L}$ ); (b) chronic kidney disease grade G5 (eGFR $<15 \mathrm{~mL} / \mathrm{min} /$ $1.73 \mathrm{~m}^{2}$ ); (c) polydipsia due to psychiatric disorders at baseline; (d) active gastrointestinal bleeding; (e) established bacterial infection including spontaneous bacterial peritonitis; (f) hepatic encephalopathy over West-Haven grade II; (g) unstable hymodynamic, renal, or respiratory state, which may suggest ongoing acute-on-chronic liver failure; (h) any patient who undergoes artificial portosystemic or peritoneovenous shunting; (i) a recent large volume paracentesis. The inclusion flow is shown in Figure S1 (Additional file). The Model for End-stage Liver Disease (MELD) score and the combined score for MELD and serum sodium concentration (MELDNa score) were calculated as previously described [28]. Baseline plasma and urine osmolality was measured by freezing point depression methods. Clinical background of study subjects is shown in Table 1 . Outcomes of the observation include: (1) BIA-defined fluid change in ICW or ECW, with a sub-analysis by whether a reduction of $1.5 \mathrm{~kg}$ or more in body weight on day eight, by which short-term response of tolvaptan [20] is defined, and (2) transplant-free survival. The included study subjects were observed with a median duration of 257.5 days (range 10-810 days).

\section{Tolvaptan regimen and data sampling}

All the study subjects were admitted and continued taking the same dose of conventional diuretics (furosemide, spironolactone, or both,) after the add-on of tolvaptan at a low dose. All admitted study subjects were on sodiumrestricted diets (less than $102 \mathrm{mmol} / \mathrm{L} \mathrm{Na}$ per day). Water restriction was not forced, and therefore, daily water intake was not monitored. Enrolled study subjects were advised about sodium restriction by a team of clinical dietitians at multiple time points including at admission, and they were monitored on their adherence to diet advices by the nursing team. Tolvaptan was initiated orally at a dose of $3.75 \mathrm{mg}$ once per day, on the first day after breakfast. The dose may be increased to $7.5 \mathrm{mg}$ once per day on the fourth day, if no adverse effects were observed. The doses from 3.75 to $7.5 \mathrm{mg}$ are relatively low as compared to the doses (30 to $60 \mathrm{mg}$ ) approved for hyponatremia in the United States or in the European Union. Serial blood tests were performed to monitor a possible abrupt elevation of serum sodium, and the onset of hepatic or renal dysfunction. The induction protocol for tolvaptan was managed mainly according to the instructions of the latest clinical practice guidelines for liver cirrhosis in Japan [29]. Since tolvaptan has been reported that free water excretion was noticed after $24 \mathrm{~h}$ of the first dose [30], body weight, blood/urine sampling, and measurement of the body composition and fluid volumes (described later) were performed at five different time points: immediately before the start of tolvaptan (time point $=0 \mathrm{~h}$ ); $6 \mathrm{~h}$ after the initial dose of tolvaptan $(6 \mathrm{~h}) ; 1$ day after the initial dose of tolvaptan (24h; on day two), 3 days after the initial dose of tolvaptan ( $72 \mathrm{~h}$; on day four); and 7 days after the initial dose of tolvaptan ( $168 \mathrm{~h}$, on day eight). Please refer to Figure S2 for the schema of data sampling.

\section{Measurement of body composition and fluid volumes using bioimpedance analysis}

Height and weight were obtained with an accuracy of $0.1 \mathrm{~cm}$ and $0.1 \mathrm{~kg}$, respectively. The body mass index (BMI) was calculated as weight $(\mathrm{kg}) /$ height $(\mathrm{m})$ squared. Bioimpedance analysis (BIA) -defined total body water $\left(\mathrm{TBW}_{\mathrm{BIA}}\right)$, extracellular water $\left(\mathrm{ECW}_{\mathrm{BIA}}\right)$, intracellular water $\left(\mathrm{ICW}_{\mathrm{BIA}}\right)$ and body cell mass were measured and analyzed by using a BIA device (InBody S10; InBody Japan, Tokyo, Japan). BIA was performed using the whole body 8-electrode approach with a multi-frequency impedance analyzer $(1,5,50,250,500$, and $1000 \mathrm{kHz})$ in the supine position, as instructed by the manufacturer. Resistance $(\mathrm{R})$, reactance $(\mathrm{Xc})$, and the phase angle (PA) were measured at each frequency. PA is the arc tangent of $\mathrm{Xc} / \mathrm{R}$ and represents the phase difference between voltage and current [31]. The PA measured at $50 \mathrm{~Hz}$ was used in this analysis. Previous studies suggested that a decreased PA correlates with decreased ICW defined by BIA $\left(\mathrm{ICW}_{\mathrm{BIA}}\right)[12,32]$. BIA has been approved and indicated for body fluid and ECW monitoring in Japan. Information about body composition, $\mathrm{ECW}_{\mathrm{BIA}}, \mathrm{ICW}_{\mathrm{BIA}}$ and $\mathrm{TBW}_{\mathrm{BIA}}$ were obtained at specific time points as was mentioned above and illustrated in Figure S2 (Additional file). Fluid volumes were compared after normalization by patient's body surface area calculated by the Mosteller Method [33].

\section{Sample size estimation}

Sample size calculation was based on the hypothesis that electrolyte-free water excretion into urine by tolvaptan results in a net movement of free water between ICW and extravascular ECW, and finally, the intravascular volume [26]. By application of the results from previous published studies: (1) tolvaptan may cause $270 \pm 241 \mathrm{ml} /$ day free water excretion [30]; (2) ECW/TBW ratio is about $0.399 \pm 0.012$ in cirrhosis patients [6]; (3) the standard deviation of ICW or ECW detected after tolvaptan in 6 cases is about $2.3 \mathrm{~L}$ [34]; (4) short-term efficacy of tolvaptan is around 62\%, [20] with two-sided testing and a presumption of $\alpha=0.05$ and $\beta=0.2$, a sample size of 7 in either responder or non-responder group, that is, a total participants of 20 , was chosen to detect a 
Table 1 Pretreatment clinical characteristics including baseline body compositions of the study subjects

\begin{tabular}{|c|c|}
\hline Variables & $\boldsymbol{N}=30$ \\
\hline Age, years & $66.5[46-87]$ \\
\hline Sex, M/F & $17(57 \%) / 13(43 \%)$ \\
\hline \multicolumn{2}{|l|}{ Etiology of liver cirrhosis } \\
\hline HCV/ Alcoholism /NASH /Others & $11(37 \%) / 10(33 \%) / 4(13 \%) / 15(17 \%)$ \\
\hline Child-Pugh-Turcotte class, B/C & $15 / 15$ \\
\hline MELD score & $13.5[8-29]$ \\
\hline MELDNa score & $18.5[8-32]$ \\
\hline MAP, $\mathrm{mmHg}$ & $82[65-106]$ \\
\hline \multicolumn{2}{|l|}{ Baseline diuretics } \\
\hline Furosemide, mg/day & $22.5[0-160]$ \\
\hline Spironolactone, mg/day & $37.5[0-100]$ \\
\hline \multicolumn{2}{|l|}{ Pre-treatment biochemical studies } \\
\hline Total bilirubin, mg/dL & $2.0[0.3-12.6]$ \\
\hline PT-INR & $1.23[0.96-2.42]$ \\
\hline Serum sodium, mmol/L & $133.8[122.3-142.8]$ \\
\hline Albumin, $\mathrm{g} / \mathrm{dL}$ & $2.4[1.6-3.9]$ \\
\hline $\mathrm{BUN}, \mathrm{mg} / \mathrm{dL}$ & $20.8[5.9-47.1]$ \\
\hline Serum creatinine, mg/dL & $1.00[0.48-2.49]$ \\
\hline $\mathrm{ALT}, \mathrm{IU} / \mathrm{L}$ & $25[7-75]$ \\
\hline GGTP, IU/L & 70 [11-359] \\
\hline AVP, $\mathrm{pg} / \mathrm{mL}$ & $1.8[0.8-6.3]$ \\
\hline Aldosterone, pg/mL & 208 [18-1200] \\
\hline Serum osmolality, mOsm/kg. $\mathrm{H}_{2} \mathrm{O}$ & 285 [250-295] \\
\hline Urine osmolality, mOsm/kg. $\mathrm{H}_{2} \mathrm{O}$ & $448[59-838]$ \\
\hline \multicolumn{2}{|l|}{ Body Compositions; baseline } \\
\hline $\mathrm{BMl}, \mathrm{kg} / \mathrm{m}^{2}$ & $23.2[16.7-32.7]$ \\
\hline Skeletal muscle index, $\mathrm{kg} / \mathrm{m}^{2}$ & $9.1[7.1-16.0]$ \\
\hline $\mathrm{TBW}_{\mathrm{BIA}} \mathrm{C}^{\mathrm{a}}, \mathrm{L} / \mathrm{m}^{2}$ & 20.4 [17.9-24.0] \\
\hline$E C W_{B I A}-C^{a}, L / m^{2}$ & $8.3[6.7-10.1]$ \\
\hline 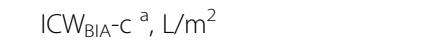 & $12.0[9.6-14.0]$ \\
\hline $\mathrm{ECW}_{\mathrm{BIA}} / \mathrm{TB} W_{\mathrm{BIA}}$ & $0.40[0.37-0.46]$ \\
\hline
\end{tabular}

Data are shown as median with the range within brackets, or numbers

Abbreviations: M Male, F Female, HCV Hepatitis virus C, MELD Model for end-stage liver disease, MAP Mean arterial blood pressure, PT-INR Prothrombin time-

international ratio, BUN Blood urea nitrogen, $A L T$ Alanine transaminase, GGTP $\gamma$ - glutamyl transpeptidase, AVP Arginine vasopressin, $B M I$ Body mass index, TBW

Total body water, BIA Bioimpedance analysis, ECW Extracellular water, ICW Intracellular water

*, $P<0.05 ;{ }^{* *}, P<0.01$; ${ }^{* * *}, P<0.0001$

${ }^{\mathrm{a}} \mathrm{TBW}_{\mathrm{BIA}} \mathrm{C}, \mathrm{ECW} \mathrm{BIA}^{-\mathrm{C}}, \mathrm{ICW}_{\mathrm{BIA}}-\mathrm{C}$ were normalized by body surface area $\left(\mathrm{m}^{2}\right)$

between-group difference of compartment free water change after tolvaptan administration, which we considered clinically meaningful. The sample size was increased to 30 participants, to account for potential dropouts.

\section{Statistical analysis}

Data were analyzed using JMP12 statistical software (SAS Institute, Inc. Cary, NC, USA) and are expressed as median with range or mean \pm standard deviation (SD), as appropriate. Non-parametric Kruskal-Wallis tests were used to assess differences between groups. Categorical variables were analyzed using chi-square analysis. Spearman correlation was used for correlation analysis. The area under the receiver operating characteristic (AUROC) analysis was performed to confirm the usefulness of various parameters for predicting outcome and generating optimal cut-offs based on the Youden Index. The DeLong method [35] was used to compare the differences between receiver operating characteristic (ROC) 
curves. To investigate the independent determining factors to predict the rapid decrease of $\mathrm{ICW}_{\mathrm{BIA}}$, logistic regression models adjusted for covariates were generated. Cumulative percentage of survival was determined by Kaplan-Meier analysis and the differences between groups were compared using a log-rank test. $P<0.05$ was considered statistically significant.

\section{Results}

\section{Baseline clinical characteristics and adverse events}

Baseline patient characteristics are shown in Table 1. Thirty patients, 13 (43\%) women and 17 (57\%) men, with a median age of 66.5 years (range $46-87$ years), were consecutively enrolled. Study participants consisted of 15 Child-Pugh-Turcotte (CPT) class B (50\%) and 15 class C (50\%) patients, with a median MELD score of 13.5 (range 8-29). No abrupt increase in serum sodium concentration was noticed during the observation period. Except for one (3.3\%) patient who suffered from
HCC rupture with subsequent pre-renal insufficiency and obviously increased serum total bilirubin and hypernatremia $(145.2 \mathrm{mmol} / \mathrm{L})$, serum creatinine concentrations and total bilirubin remained stable for most patients irrespective of their responses to add-on lowdose tolvaptan (Figure S3 in Additional file).

\section{Sub-analysis by short-term response to tolvaptan}

Sixteen patients (53\%) with $1.5 \mathrm{~kg}$ or more body weight reduction on day eight were defined as responders to addon tolvaptan at low doses, and the remaining 14 patients (47\%) as non-responders (Fig. 1a-b). In responders, the ECW to TBW ratio (ECW/TBW) decreased gradually after the administration of tolvaptan and was significantly lower on day eight than on day 0 (Fig. 1c). This phenomenon was not observed in non-responders.

In univariate analysis (Table 2), age, sex, diuretics dosage, baseline serum sodium levels, urinary osmolality, and baseline body compositions evaluated by BIA, including

\section{a}

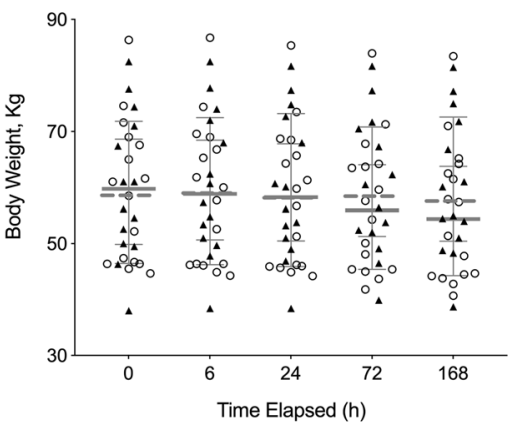

C

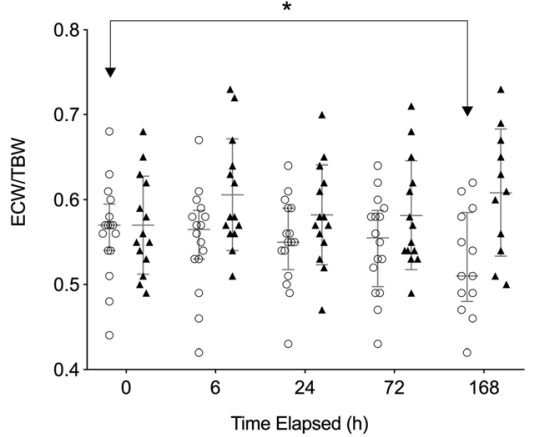

b

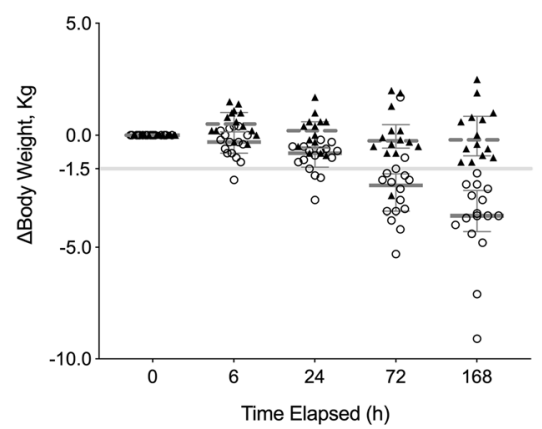

d

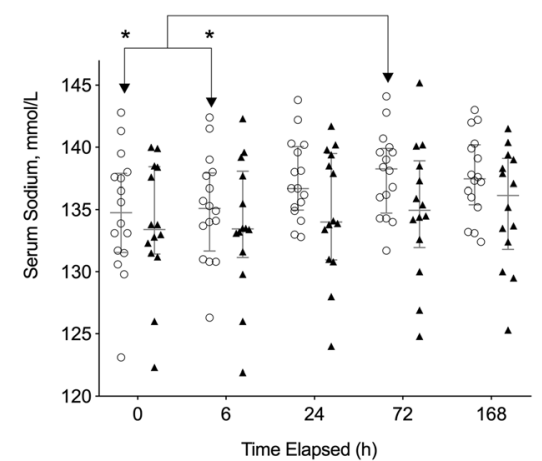

Fig. 1 Serial monitoring of body weight, changes in BW, extracellular water to total body water ratio, and serum sodium concentration after addon tolvaptan at low doses. Body weight (BW, in kilograms, $\mathbf{a}$, changes in body weight $(\Delta \mathrm{BW}$, in kilograms, $\mathbf{b}$, the extracellular water/total body water (ECW/TBW) ratio (using the bioimpedance analysis [BIA] method, $\mathbf{c}$, and serum sodium concentration (in mmol/L, $\mathbf{d}$ were monitored as illustrated in Figure S2, at 0, 6, 24, 72, and $168 \mathrm{~h}$ (missing data: 6 for BIA at $168 \mathrm{~h}$ ) after add-on tolvaptan at low doses was administered. Patients with $1.5 \mathrm{~kg}$ or more body weight reduction (horizontal light gray line in b) on day eight were defined as responders (open circles); all other patients were defined as non-responders (closed triangles). Medians with interquartile ranges are shown in bars. Abbreviations: ECW, extracellular water; TBW, total body water. ${ }^{*}, P<0.05$ 
Table 2 Comparison of clinical characteristics in short-term responders and non-responders to tolvaptan

\begin{tabular}{|c|c|c|c|}
\hline Variables & Responders & Non-responders & $P$ (uni) \\
\hline $\mathrm{N}$ & $16(53 \%)$ & $14(47 \%)$ & - \\
\hline Age, years & $71[46-87]$ & $65[51-80]$ & 0.227 \\
\hline Sex, M/F & $8 / 8$ & $9 / 5$ & 0.484 \\
\hline$\Delta B W$, at day $8, \mathrm{~kg}$ & $-3.6[-9.1$ to -1.7$]$ & $-0.2[-1.2$ to +2.5$]$ & $<.001^{* * *}$ \\
\hline Child-Pugh-Turcotte class, B/C & $10 / 6$ & $5 / 9$ & 0.272 \\
\hline MELD score & $13[8-22]$ & 16 [8-29] & 0.164 \\
\hline MELDNa score & $17[8-30]$ & $21[12-32]$ & 0.129 \\
\hline MAP, mmHg & $81[65-104]$ & $82[76-106]$ & 0.533 \\
\hline \multicolumn{4}{|l|}{ Baseline diuretics } \\
\hline Furosemide, mg/day & $22.5[0-60]$ & $30[0-160]$ & 0.949 \\
\hline Spironolactone, mg/day & 50 [25-100] & $37.5[0-75]$ & 0.443 \\
\hline \multicolumn{4}{|l|}{ Pre-treatment biochemical studies } \\
\hline Total bilirubin, mg/dL & $1.5[0.3-12.6]$ & $3.5[1.1-8.3]$ & $0.034^{*}$ \\
\hline PT-INR & $1.20[0.96-1.75]$ & $1.29[1.03-2.42]$ & 0.429 \\
\hline Serum sodium, mmol/L & $134.8[123.1-142.8]$ & $133.4[122.3-40.0]$ & 0.692 \\
\hline Albumin, g/dL & $2.5[1.6-3.1]$ & $2.4[1.8-3.9]$ & 0.917 \\
\hline $\mathrm{BUN}, \mathrm{mg} / \mathrm{dL}$ & $18.3[5.9-47.1]$ & 23.6 [11.9-46.3] & 0.085 \\
\hline Serum creatinine, mg/dL & $1.00[0.48-2.49]$ & $1.00[0.48-2.13]$ & 0.819 \\
\hline $\mathrm{ALT}, \mathrm{IU} / \mathrm{L}$ & $19.5[7-45]$ & $41[11-75]$ & $0.004^{* *}$ \\
\hline GGTP, IU/L & $59.5[14-264]$ & $92[11-359]$ & 0.262 \\
\hline AVP, pg/mL & $1.35[0.8-5.1]$ & $2.3[1.2-6.3]$ & $0.026^{*}$ \\
\hline Aldosterone, pg/mL & 113 [18-407] & 316 [107-1200] & $0.013^{*}$ \\
\hline Serum osmolality, mOsm/kg. $\mathrm{H}_{2} \mathrm{O}$ & 286 [250-290] & $282[273-295]$ & 0.880 \\
\hline Urine osmolality, mOsm/kg. $\mathrm{H}_{2} \mathrm{O}$ & 448 [272-691] & 452 [59-838] & 0.350 \\
\hline \multicolumn{4}{|l|}{ Body Compositions; baseline } \\
\hline $\mathrm{BMI}, \mathrm{kg} / \mathrm{m}^{2}$ & $23.1[17.6-32.7]$ & $23.7[16.7-27.7]$ & 0.574 \\
\hline Skeletal muscle index, $\mathrm{kg} / \mathrm{m}^{2}$ & $9.1[7.4-16.0]$ & $9.3[7.1-11.5]$ & 0.603 \\
\hline $\mathrm{TBW}_{\mathrm{BIA}} \mathrm{C}^{\mathrm{a}}, \mathrm{L} / \mathrm{m}^{2}$ & $20.2[18.0-22.5]$ & $20.8[17.9-24.0]$ & 0.575 \\
\hline$E C W_{B I A}-C^{a}, L / m^{2}$ & $8.3[7.2-9.2]$ & $8.3[6.7-10.1]$ & 0.755 \\
\hline $\mathrm{ICW}_{\mathrm{BIA}}-\mathrm{C}^{\mathrm{a}}, \mathrm{L} / \mathrm{m}^{2}$ & $12.0[10.5-13.7]$ & $12.4[9.6-14.0]$ & 0.418 \\
\hline $\mathrm{ECW}_{\mathrm{BIA}} / \mathrm{TB} W_{\mathrm{BIA}}$ & $0.40[0.38-0.43]$ & $0.40[0.37-0.46]$ & 0.418 \\
\hline
\end{tabular}

Data are shown as median with the range within brackets, or numbers

Abbreviations: $M$ Male, F Female, HCV Hepatitis virus C, MELD Model for end-stage liver disease, MAP Mean arterial pressure, PT-INR Prothrombin time- international ratio, BUN Blood urea nitrogen, ALT Alanine transaminase, GGTP $\gamma$ - glutamyl transpeptidase, AVP Arginine vasopressin, BMI Body mass index, TBW Total body water, BIA Bioimpedance analysis, ECW Extracellular water, ICW Intracellular water * $P<0.05 ; * *, P<0.01 ; * * *, P<0.0001$

${ }^{\mathrm{a}} \mathrm{TBW}_{\mathrm{BIA}}-\mathrm{C}, \mathrm{ECW}_{\mathrm{BIA}}-\mathrm{C}, \mathrm{ICW}_{\mathrm{BIA}}-\mathrm{C}$ were normalized by body surface area $\left(\mathrm{m}^{2}\right)$

the skeletal muscle index, and fluid volumes normalized by body surface areas, did not show any significant differences when comparing responders and non-responders. Responders had significantly lower levels of background total bilirubin $(P=0.034)$, alanine aminotransferase (ALT) $(P=0.004)$, AVP $(P=0.026)$, and aldosterone $(P=0.013)$ than non-responders. Responders also tended to be less azotemic $(P=0.085)$. Responders and non-responders did not differ in background presentation regarding $\mathrm{HCC}$ or portal hypertension (Table S1 in Additional file).
Four (13\%) of our study subjects had baseline serum sodium concentrations below $130 \mathrm{mmol} / \mathrm{L}$, the threshold defined for hyponatremia [36]. However, 17 (57\%) subjects had serum sodium concentrations below $135 \mathrm{mmol} / \mathrm{L}$, the threshold for increased mortality in patients listed for liver transplantation [28]. Serum sodium concentrations of responders to addon, low-dose tolvaptan increased significantly at $72 \mathrm{~h}$ compared to those of non-responders (Fig. 1d), although the baseline serum sodium concentration did 
not differ significantly between responders and nonresponders (Table 1).

\section{Temporal dynamics of compartmental fluid volumes evaluated by bioimpedance analysis}

At $6 \mathrm{~h}$ after the first administration, a dramatic and rapid decrease in BIA-defined $\mathrm{ICW}_{\mathrm{BIA}^{-\mathrm{C}}}$ was noticed in responders, followed by a more gradual decrease in $\mathrm{ECW}_{\mathrm{BIA}^{-\mathrm{C}}}$ (Fig. 2a-b). ICW $\mathrm{BIA}^{-\mathrm{C}}$ was significantly lower in responders at $6 \mathrm{~h}, 24 \mathrm{~h}$, and $168 \mathrm{~h}$ (Fig. 2a), and ECWBIA $^{-C}$ was significantly lower at $6 \mathrm{~h}$ and $168 \mathrm{~h}$ (Fig. 2b), than in non-responders. In responders, but not in nonresponders, significant decreases in both $\mathrm{ICW}_{\mathrm{BIA}^{-}}$- and $\mathrm{ECW}_{\mathrm{BIA}} \mathrm{A}^{\mathrm{c}}$ were observed (Fig. 2a-b).

The delay in the relative responses to $\mathrm{ICW}_{\mathrm{BIA}}$ and $\mathrm{ECW}_{\text {BIA }}$ over time might imply a fluid volume shift from the $\mathrm{ICW}_{\mathrm{BIA}}$ to the $\mathrm{ECW}_{\mathrm{BIA}}$. The differences between responders and non-responders were most prominent and significant at $6 \mathrm{~h}$ after first administration of add-on tolvaptan $\left(\triangle \mathrm{ICW} \mathrm{BIA}_{\mathrm{BI}} \%-6 \mathrm{~h}\right)$. In responders, a gradual reduction in the change in $\mathrm{ECW}\left(\triangle \mathrm{ECW}_{\mathrm{BIA}} \%\right)$ was observed starting at around $24 \mathrm{~h}$ after administration of add-on tolvaptan, and continued thereafter (Fig. 2c). Change of the phase angle measured at $50 \mathrm{~Hz}$ by bioimpedance analysis was highly and significantly associated with $\triangle \mathrm{ICW}_{\mathrm{BIA}} \%-6 \mathrm{~h}$ (Fig. 3). Detailed changes of resistance and reactance pre and post tolvaptan in individual cases are shown in Figure S4 (Additional file).

\section{Rapid and early decrease in ICW $\mathrm{CWIA}_{\mathrm{A}}$ predicts short-term efficacy of add-on tolvaptan at low doses}

Rate of ICW $\mathrm{IIA}_{\mathrm{BI}}$ volume change at $6 \mathrm{~h}$ after the first administration of add-on, low-dose tolvaptan $\left(\triangle \mathrm{ICW}_{\mathrm{BIA}} \%\right.$ $6 \mathrm{~h}$ ), along with other factors that showed a significant or a tendency of significant difference between responders and non-responders (Table 1), were included in the ROC analyses to confirm their potential for response prediction (Fig. 4 and Table S2 in the Additional file). A $\triangle \mathrm{ICW}_{\mathrm{BIA}} \%-6 \mathrm{~h}$ below 0 , indicating a decreased $\mathrm{ICW}_{\mathrm{BIA}}$ in response to tolvaptan compared to baseline, resulted to have the most significant diagnostic value (AUC $=0.98$ ), as assessed using the DeLong method (Table S2 in the Additional file).

\section{Clinical parameters that predicted a rapid and early decrease of $\mathrm{ICW}_{\mathrm{BIA}}$ in response to tolvaptan}

In Table 3, clinical baseline parameters were compared between cases whose ICW $\mathrm{IIA}_{\text {BIA }}$ decreased or increased after $6 \mathrm{~h}$ of the first dose of tolvaptan. Age, sex, baseline diuretics, serum sodium, creatinine, serum and urine osmolality did not differ significantly. Baseline MELDNa score, total bilirubin, ALT, serum aldosterone were significantly factors predicting a rapid and early decrease of $\mathrm{ICW}_{\mathrm{BIA}}$ by univariate analysis. In multivariate analysis, serum aldosterone, along with blood urea nitrogen were found to be possible significant predictive factors for the rapid and early decrease of $\mathrm{ICW}_{\mathrm{BIA}}$, after adjustment for MELDNa, total bilirubin, ALT, and/or AVP in various models (Table S3 in the Additional file).

After the first dose of tolvaptan, a rapid decrease in urine osmolality was observed in both groups regardless of the change of ICW $_{\text {BIA }}$ volumes at $6 \mathrm{~h}$ after the first dose of tolvaptan (Fig. 5a). However, in patients whose $\mathrm{ICW}_{\text {BIA }}$ decreased at $6 \mathrm{~h}$, a significant increase in serum sodium was observed at 24 and $72 \mathrm{~h}$, and the tendency still remained at $168 \mathrm{~h}$. Additionally, blood urea nitrogen (BUN) levels showed a slower and gradual change; however, this tended to increase in patients whose ICW $_{\text {BIA }}$ decreased at $6 \mathrm{~h}$ but stayed relatively stable in those whose ICW $\mathrm{IIA}_{\mathrm{BI}}$ increased at $6 \mathrm{~h}$ (Fig. 5b). The increase in combined rate of change in serum sodium and BUN at 6 h, i.e., $\Delta(\mathrm{Na}, \mathrm{UN}) \%-6 \mathrm{~h}$, was significantly associated with decreased ICW $\mathrm{IIA}_{\mathrm{BI}}$ at $6 \mathrm{~h}$ and the short-term response of add-on tolvaptan (Fig. 5c), as well as with changes in the rates of $\mathrm{ICW}_{\mathrm{BIA}}$ and $\mathrm{ECW}_{\mathrm{BIA}}$ at $6 \mathrm{~h}$ (Fig. $5 \mathrm{~d}$ ).

\section{Rapid and early decrease in $\mathrm{ICW}_{\mathrm{BIA}}$ in response to tolvaptan significantly predicted a better clinical prognosis in decompensated cirrhosis}

During the observation period, four patients underwent liver transplantation, and 14 patients died due to endstage liver disease. The transplant-free survival is $40 \%$. As shown in Fig. 6, although the response to add-on tolvaptan showed a tendency of longer survival in this study cohort ( $P=0.12$, Fig. $6 a)$, the rapid and early decrease in $\mathrm{ICW}_{\mathrm{BIA}}$ at $6 \mathrm{~h}$ after the first dose of tolvaptan significantly differentiated two groups of patients in terms of long-term survival ( $P=0.02$, Fig. $6 \mathrm{~b})$. Neither baseline MELD score nor Child-Pugh grade could differentiate the survival of patients beyond 90 days of observation (Fig. 6c-d); instead, the baseline MELDNa score tended to predict survival $(P=0.07$, Fig. 6e). Despite having excluded five cases with advanced HCC (Barcelona Clinic Liver Cancer stage $\mathrm{C}$ or $\mathrm{D}$ ) from the analysis, the rapid $\mathrm{ICW}_{\mathrm{BIA}}$ decrease in response to tolvaptan still significantly correlated with better long-term survival $(P=0.048$; Figure S5 in the Additional file).

\section{Discussion}

In the current study, we demonstrated a rapid and early decrease in phase angle (reactance), e.g. reduced ICW assessed by BIA after adding low dose tolvaptan, correlated significantly with short-term efficacy of amelioration of body fluid retention and the long-term survival. $\triangle \mathrm{ICW}_{\mathrm{BIA}} \%-6 \mathrm{~h}$ predicted short-term efficacy of add-on tolvaptan at an accuracy of $97 \%$ and long-term survival in our study cohort. To our knowledge, this is the first real world clinical practice-based study to show the 


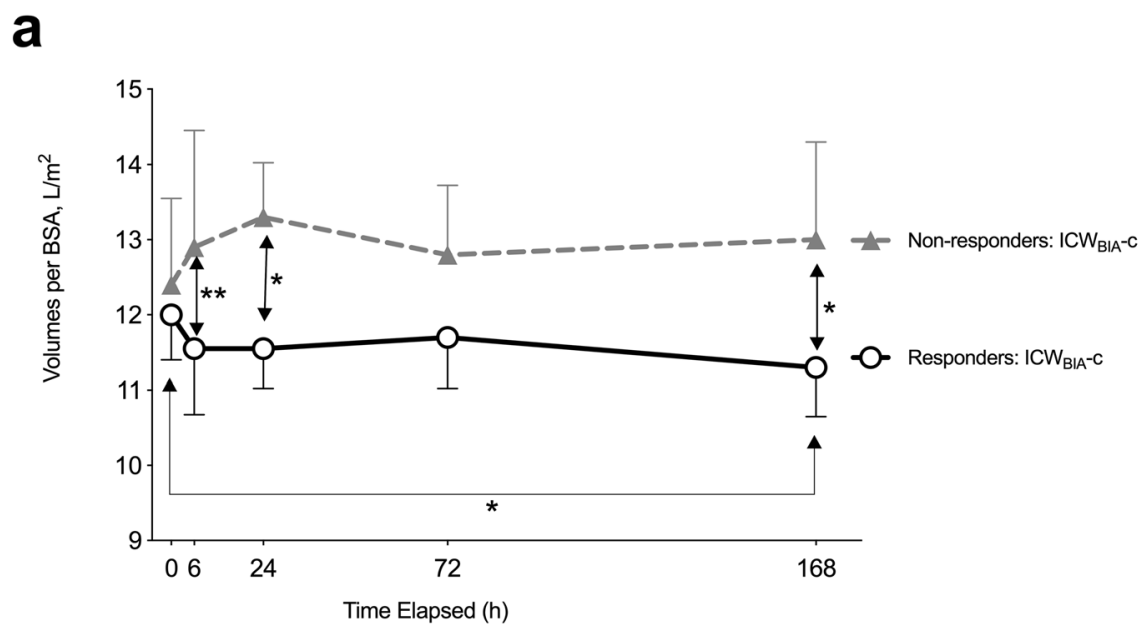

b

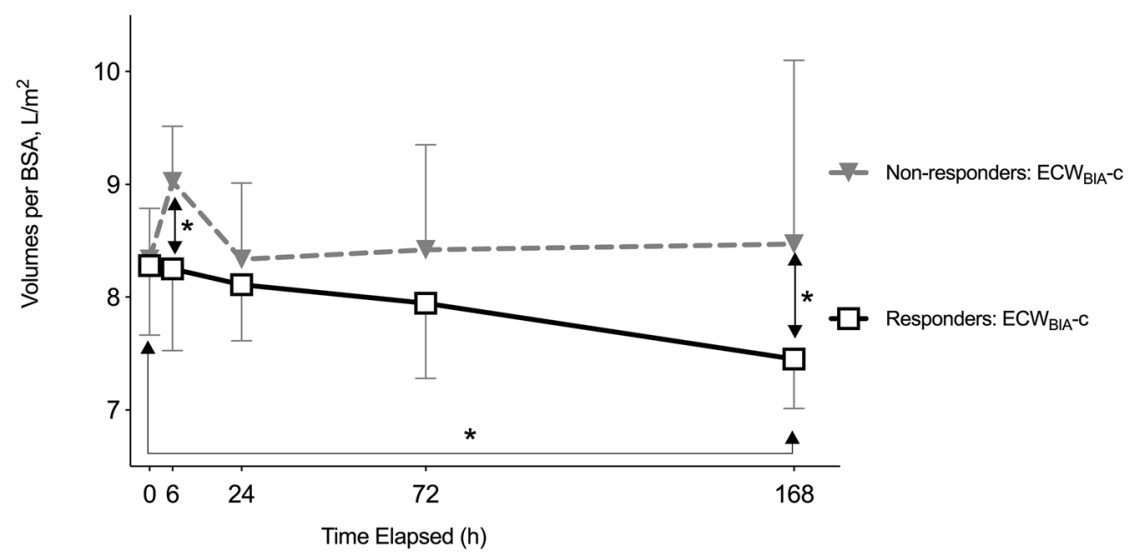

C

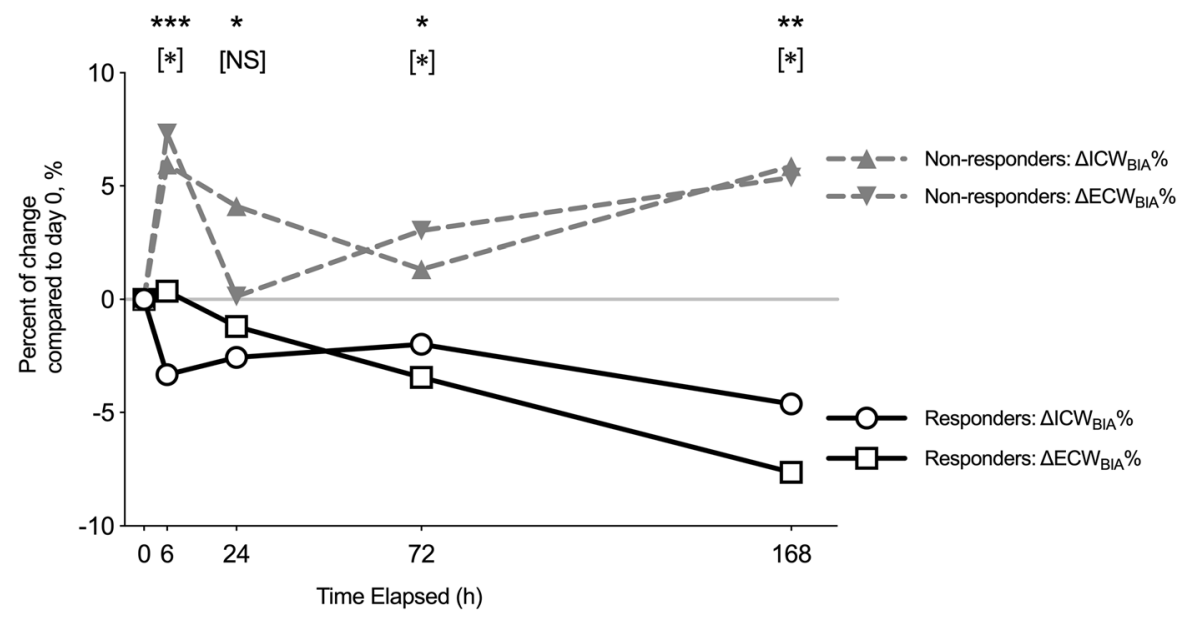

Fig. 2 (See legend on next page.)

usefulness of BIA-assessed ICW change in response to electrolyte-free water excretion caused by V2 antagonism for both short-term efficacy and long-term survival, in patients of decompensated cirrhosis.
Kogiso et al. reported that ECW/TBW ratio significantly decreased in eight long-term responders to tolvaptan [19]. We also observed the same tendency in responders in this current study (Fig. 1c). BIA is also a 
(See figure on previous page.)

Fig. 2 Serial monitoring of bioimpedance-defined intracellular water, extracellular water, and the percent of change in both parameters by bioimpedance analysis after add-on tolvaptan at low doses. Bioimpedance-defined intracellular body water standardized by body surface area (BSA) (ICW $\mathrm{BIA}^{-} \mathrm{C}, \mathrm{L} / \mathrm{m}^{2}$, $\mathbf{a}$, extracellular body water standardized by BSA (ECW $\mathrm{BIA}^{-} \mathrm{C}, \mathrm{L} / \mathrm{m}^{2}, \mathbf{b}$, and percent of change in both compartments compared to day 0 (panel c) were monitored as illustrated in Figure S2, at 0, 6, 24, 72, and 168 (missing data: 6 for BIA at 168 h) hours after addon tolvaptan at low doses was administered. Patients with $1.5 \mathrm{~kg}$ or more body weight reduction on day eight were defined as responders (open circles for ICW $\mathrm{BIA}_{\mathrm{A}}$ open squares for ECW BIA; with thin lines), and others as non-responders (closed upward triangles for ICW BIA; Closed downward triangles for ECW BIA; with dashed lines). Medians with interquartile ranges are shown in bars. In panel $C$, $P$-values compared ICWs with respect to response are shown, whereas $P$-values referring to $E_{C W}$ BIA, $_{\text {, }}$ comparisons are shown in brackets. Abbreviations: ICW, intracellular water; ECW, extracellular water; BIA; bioimpedance analysis; BSA, body surface area; NS, not significant. ${ }^{*}, P<0.05 ;{ }^{* *}, P<0.01$; ${ }^{* * *}, P<0.0001$

useful tool to demonstrate that the loss of body weight in responders is mainly due to decreased TBW, rather than reduced body cell mass. Selberg et al. showed that higher BIA-derived phase angle (assumed to be determined by tissue cellularity, tissue hydration, and membrane potential) in 305 patients of liver cirrhosis predicted poorer survival [37]. This is coherent to our finding that a decreased phase angle after add-on tolvaptan (decreased $\mathrm{ICW}_{\mathrm{BIA}}$ ) predicted better prognosis (Fig. 3).

Masuda et al. reported that tolvaptan reduced both ICW and ECW, evaluated by BIA in six patients with chronic kidney disease [34]. Masuda et al. also presumed

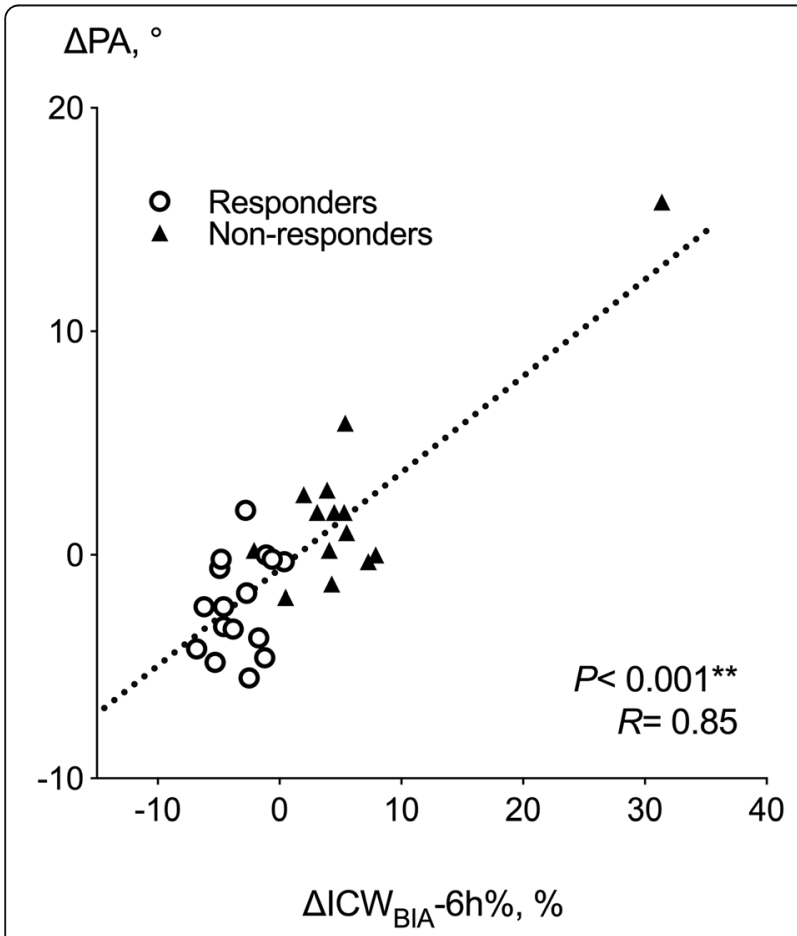

Fig. 3 Correlation analysis of the change of the phase angle highly and the percent change of bioimpedance-defined intracellular water at $6 \mathrm{~h}$ after add-on tolvaptan. Patients with $1.5 \mathrm{~kg}$ or more body weight reduction on day eight were defined as responders (open circles), and others as non-responders (closed triangles). Phase angle (PA) was measured at $50 \mathrm{~Hz}$. ICW, intracellular water; BIA, bioimpedance analysis; $R$, correlation coefficient. ${ }^{* *}, P<0.001$ that a rise in serum osmolality and resultant fluid shift from intracellular to interstitial and intravascular spaces would occur immediately after the administration of tolvaptan. With BIA, Nagayama et al. demonstrated different effects on fluid distribution between tolvaptan and furosemide in a patient with liver cirrhosis and chronic kidney disease [38]. Nomoto et al. showed that in patients with acute decompensated heart failure, diuresis due to tolvaptan caused no significant change of $\mathrm{ECW} / \mathrm{ICW}$ ratio by using BIA, while that due to conventional diuretics decreased ECW/ICW ratio [11]. This finding suggested a net reduction of ICW might characterize tolvaptan from conventional diuretics. In the current study, we showed that a decrease in ICW $\mathrm{BIA}_{\text {BA }}$ occurred as soon as $6 \mathrm{~h}$ after the first dose of tolvaptan (Fig. 2), and its degree correlated with the increase in BUN and serum sodium (Fig. 5), which are the major determinant factors for both serum osmolality and urine-concentrating mechanisms in the renal medullary loops of Henle [39]. The increase in serum sodium and BUN (Fig. 4b) might help to induce a shift of free water from the intracellular compartment, which is less prominent in non-responders. Higher baseline BUN has also been reported as a negative predictive factor for the efficacy of tolvaptan for cirrhotic ascites $[40,41]$. In this present study, the baseline BUN tented to be higher $(P=$ 0.06, Table 1), and the follow-up BUN levels remained high in the non-responders (Fig. 5b).

The reason for why early extractable ICW $\mathrm{BIA}_{\mathrm{BA}}$ after $\mathrm{V} 2$ antagonism unexpectedly correlates with survival (Fig. 5) is not easy to explain. Hiramine $\mathrm{Y}$ et al. demonstrated a positive effect of add-on tolvaptan on the prognosis of patients with cirrhotic ascites by analyzing 628 patients retrospectively, compared to conventional diuretics alone [42]. Higher baseline BUN levels, that are supposedly a result of the chronic vascular under-filling state due to cirrhosis, might also be a result of chronic diuretic use for ascites. Sone et al. showed that the chronic administration of furosemide, a loop diuretic agent, greatly reduced renal medullary contents of organic osmolytes in a murine model [43]. Conversely, a selective V2 antagonist did not produce a sufficient decrease in the content of organic osmolytes; while, an increase in taurine levels, an effective organic osmolyte, was observed following exposure to a selective V2 antagonist in a murine 


\section{a}

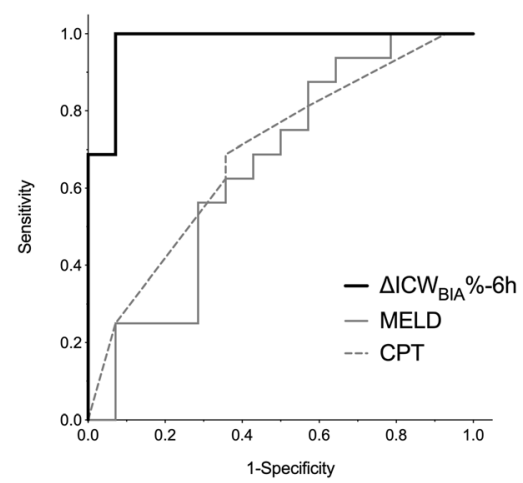

b

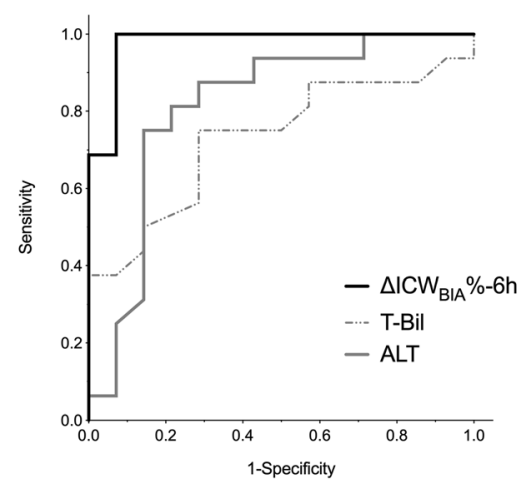

C

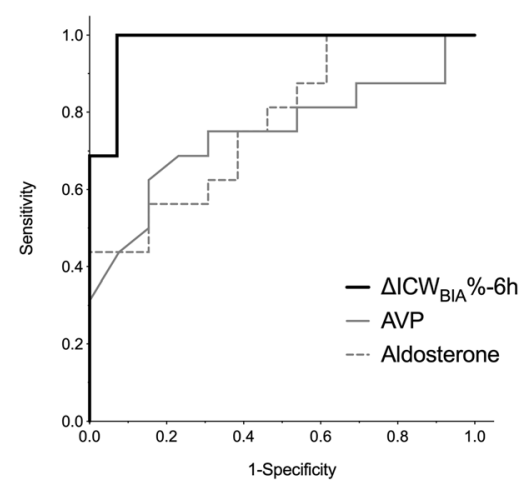

Fig. 4 Receiver operating characteristic curves for predicting response to add-on tolvaptan. Comparison of the prognostic value of various parameters for the discrimination of responders and non-responders to add-on tolvaptan treatment is shown. The receiver operating characteristic (ROC) curves for the percent change in bioimpedance-defined intracellular water at $6 \mathrm{~h}$ after add-on tolvaptan $\left(\Delta \mathrm{ICW} \mathrm{BIA}_{\mathrm{A}} \%-6 \mathrm{~h}\right)$, and other parameters are shown. Detailed statistics, including statistical comparison of the ROC curves by the DeLong method, are presented in Table S2. Abbreviations: MELD, model for end-stage liver disease; CPT, Child-Pugh-Turcotte; T-Bil, total bilirubin; AST, aspartate aminotransferase; ALT, alanine aminotransferase; AVP, arginine vasopressin

Table 3 Comparison of clinical characteristics in cases whose ICW BIA decreased or increased after six hours of add-on tolvaptan

\begin{tabular}{|c|c|c|c|}
\hline Variables & $I_{\text {ICW }}$ Decreased & $\mathrm{ICW}_{\text {BIA }}$ Increased & $P$ (uni) \\
\hline $\mathbf{N}$ & 17 (57\%) & $13(43 \%)$ & - \\
\hline Age, years & $69[46-87]$ & $65[51-80]$ & 0.325 \\
\hline Sex, M/F & $9 / 8$ & $8 / 5$ & 0.721 \\
\hline \multicolumn{4}{|l|}{ Background clinical profile } \\
\hline Child-Pugh-Turcotte B/C & $11 / 6$ & $4 / 9$ & 0.139 \\
\hline MELD score & 13 [8-23] & 16 [8-29] & 0.075 \\
\hline MELDNa score & $17[8-30]$ & 21 [13-32] & $0.047^{*}$ \\
\hline MAP, $\mathrm{mmHg}$ & $81[65-104]$ & 82 [76-106] & 0.818 \\
\hline \multicolumn{4}{|l|}{ Baseline diuretics } \\
\hline Furosemide, mg/day & $25[0-160]$ & 20 [0-80] & 0.589 \\
\hline Spironolactone, mg/day & $25[0-100]$ & $50[0-75]$ & 0.825 \\
\hline \multicolumn{4}{|l|}{ Pre-treatment biochemical studies } \\
\hline Total bilirubin, mg/dL & $1.5[0.3-12.6]$ & $3.5[1.1-8.3]$ & $0.040^{*}$ \\
\hline PT-INR & $1.20[0.96-1.75]$ & $1.33[1.03-2.42]$ & 0.476 \\
\hline Serum sodium, mmol/L & $135.6[123.1-142.8]$ & $133[122.3-40.0]$ & 0.368 \\
\hline Albumin, $\mathrm{g} / \mathrm{dL}$ & $2.6[1.6-3.1]$ & $2.3[1.8-3.9]$ & 0.867 \\
\hline $\mathrm{BUN}, \mathrm{mg} / \mathrm{dL}$ & $18.2[5.9-47.1]$ & $25.3[11.9-46.3]$ & 0.054 \\
\hline Serum creatinine, mg/dL & $0.99[0.48-2.49]$ & $1.01[0.48-2.13]$ & 0.786 \\
\hline $\mathrm{ALT}, \mathrm{IU} / \mathrm{L}$ & $20[7-75]$ & 39 [11-69] & $0.019^{*}$ \\
\hline GGTP, IU/L & 64 [14-264] & 95 [11-359] & 0.315 \\
\hline AVP, pg/mL & $1.4[0.8-5.1]$ & $2.3[1.2-6.3]$ & 0.076 \\
\hline Aldosterone, $\mathrm{pg} / \mathrm{mL}$ & 116 [18-407] & 333 [107-1200] & $0.012^{*}$ \\
\hline Serum osmolality, mOsm/kg. $\mathrm{H}_{2} \mathrm{O}$ & 287 [250-295] & 280 [273-293] & 0.659 \\
\hline Urine osmolality, mOsm $/ \mathrm{kg} . \mathrm{H}_{2} \mathrm{O}$ & $441[272-691]$ & $485[59-838]$ & 0.267 \\
\hline
\end{tabular}

Data are shown as median with the range within brackets, or numbers

Abbreviations: $M$ Male, F Female, MELD Model for end-stage liver disease, Map Mean arterial pressure, PT-INR Prothrombin time- international ratio, BUN Blood urea nitrogen, ALT Alanine transaminase, GGTP $\gamma$ - glutamyl transpeptidase, AVP Arginine vasopressin

*, $P<0.05 ;{ }^{* *}, P<0.01$ 


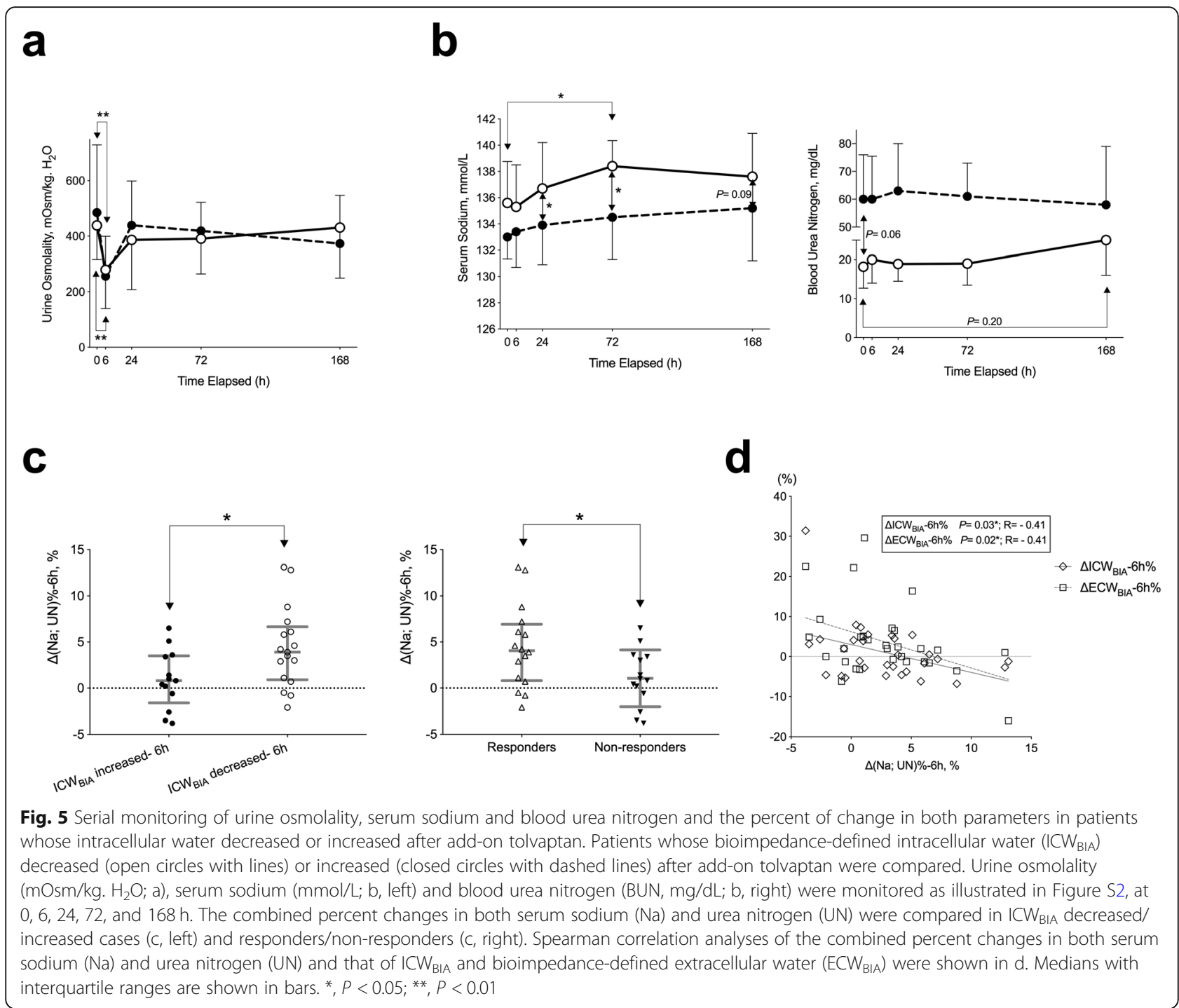

model [44]. Therefore, a well-preserved urine-concentrating ability that implicates preserved renal medullary osmolyte levels, favors a transient and immediate rise in osmolality after V2 antagonism, and is also assumed to be required for the immediate extraction of $\mathrm{ICW}_{\mathrm{BIA}}$, a positive predictive parameter for tolvaptan efficacy in this study. Moreover, more severe hyponatremia is associated with an increase in $\mathrm{ICW}_{\mathrm{BIA}}$ after add-on tolvaptan in our study cohort (Fig. 5b, left). This was coherent with a previous study showing that maintained serum sodium over $140 \mathrm{mmol} / \mathrm{L}$ is a significant predictor of response to tolvaptan [22]. Hyponatremia in cirrhosis is associated with more intractable ascites and greater impairments of renal function [36]. A higher degree of extractable $\mathrm{ICW}_{\mathrm{BIA}}$ with low-dose of tolvaptan treatment might also suggest better-preserved renal function, and therefore, better survival potential.

Base on previous studies until early 2000s, some experts reported that cautions might be needed for the explanation of cross-sectional quantification of ICW or ECW by using BIA, especially in patients with altered body compositions such as kidney, heart, or liver diseases [4, 45]. In this current study, we used the longitudinal comparison in each individual for assessment, in order to lessen confounding effects such as possible anthropometric factors. In addition, in order to overcome the limitation of the direct use of BIA-defined volumes in diseased state, the use of BIA-derived "phase angle" to define changes in body compositions in cirrhosis has been focused [37, 46]. We also showed a significant and high correlation between the change of phase angle and $\mathrm{ICW}_{\mathrm{BIA}}$ in a cross-sectional analysis (Fig. 3).

Still, there are other major limitations to this study. First, even though add-on low dose tolvaptan for cirrhotic ascites is generally approved and used in daily practice in Japan, it is still not a standard treatment internationally. 


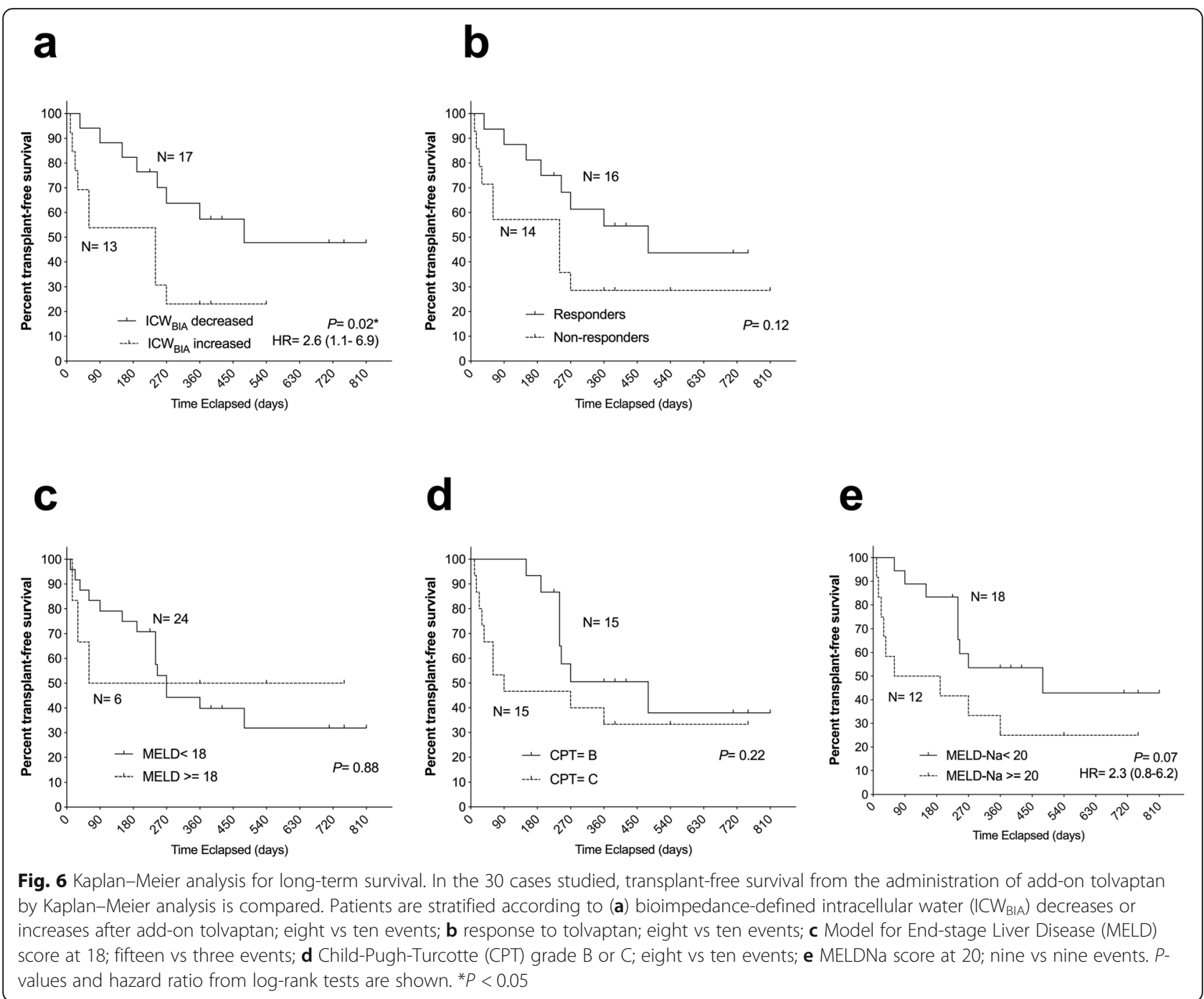

This point might limit applicability of the results yielded by this study. In addition, although we monitored body composition through serial measurement of BIA within 1 week after administration of low-dose tolvaptan, the small sample size without a proper control group might limit the generalizability of this observation and made it difficult to control for effects of possible confounders with regard to long-term survival, which might cause selection bias. Further investigations are still warranted to determine whether and how low dose tolvaptan improves survival in patients with cirrhosis in a prospective setting. Moreover, although BIA for assessment of body composition is generally considered to be reproducible and accurate with few cost and invasiveness concerns [5], and the application of phase angle might meet some needs in populations with altered body composition, it is still not fully validated in many edematous states. This is possibly why BIA is not routinely applied in practice until now. Finally, since the concomitant use of conventional diuretics was maintained during the present study, the effect of monotherapy with tolvaptan to change fluid volumes in different compartments was not examined.

\section{Conclusions}

With the serial monitoring of fluid status by BIA, we found that the rapid and early decrease in ICW $\mathrm{IIA}$ predicted short-term efficacy of add-on tolvaptan at low doses. The $\mathrm{ICW}_{\mathrm{BIA}}$ decrease in response to add-on tolvaptan was also predictive of survival in patients with decompensated cirrhosis. Even though there are still many technical limitations remaining, we believe that based on the evidence provided by this study, BIAdefined water compartment monitoring might play a role in the management and care for decompensated cirrhotic patients with ascites in the future. 


\section{Supplementary information}

Supplementary information accompanies this paper at https://doi.org/10. 1186/s12876-020-01205-2.

Additional file 1 Figure $\mathbf{S 1}$ Inclusion flow of the study subjects. Figure S2 Study schema for tolvaptan administration and the serial monitoring of body compartments and biochemical studies. Figure S3 Serial monitoring of estimated glomerular filtration rate and total bilirubin of the study subjects after add-on tolvaptan at low doses. Figure S4 The resistance-reactance path graphs for responders (panel A) and nonresponders (panel B) pre and post add-on tolvaptan at frequency of 50 kHz. Figure S5 Kaplan-Meier analysis for long-term survival as stratified by bioimpedance-defined intracellular water response to add-on tolvaptan in cases without advanced hepatocellular carcinoma. Table S1 Pretreatment clinical characteristics regarding hepatocellular carcinoma and portal hypertension of the study subjects Table S2 Comparison between areas under the receiver operating characteristic curve of clinical parameters for differentiation between responders and non-responders. Table S3 Models of multivariate analysis for predicting the rapid decrease of ICW $\mathrm{BIA}$

\section{Abbreviations}

ALT: Alanine aminotransferase; AQP: Aquaporin; AVP: Arginine vasopressin; BIA: Bioimpedance analysis; CPT: Child-Pugh-Turcotte; ECW: Extracellular water; HCC: Hepatocellular carcinoma; ICW: Intracellular water;

$I_{\text {ICW }}$ : Bioimpedance analysis-defined intracellular water; MELD: Model for End-stage Liver Disease; TBW: Total body water; YLDs: Years lived with disability

\section{Acknowledgements}

Not applicable.

\section{Authors' contributions}

$H E, H S$, and TK conceived and designed the study. SS, PC, NT, KO, AYa, RM, $\mathrm{AYO}, \mathrm{Al}$, and $\mathrm{KY}$ acquired data. SS, PC, NN, HE, HS, and TK analyzed and interpreted the data. SS and PC drafted the manuscript. NN, NT, KO, AYa, RM, $A Y O, A I, K Y, H E, H S$, and TK critically revised the manuscript for important intellectual content. All authors approved the final version of the manuscript and agreed to be accountable for all aspects of the work.

\section{Funding}

The authors have nothing to declare.

\section{Availability of data and materials}

All datasets generated during the current study are available from the corresponding authors on reasonable request, and the results from all data analyzed during this study are included in the published article.

\section{Ethics approval and consent to participate}

This study was specifically approved before its start by the institutional review board of the Keio University School of Medicine (No. 20150267) in accordance with the guidelines of the 1975 Declaration of Helsinki (2008 revision). Recruited study subjects were provided with written informative study materials during consent interview, and oral informed consent was recorded with formal documentation in the medical records, which included study participation and analysis of clinical data. Because of the observational nature of study and the non-invasiveness of body fluid monitoring using BIA, and the institutional review board approved the use of oral consent.

\section{Consent for publication}

Not applicable.

\section{Competing interests}

The authors declare that they have no competing interests.

\section{Author details}

${ }^{1}$ Division of Gastroenterology and Hepatology, Department of Internal Medicine, Keio University School of Medicine, 35 Shinanomachi, Shinjuku-ku, Tokyo 160-8582, Japan. Department of Gastroenterology and Hepatology, Tokyo Dental College Ichikawa General Hospital, 5-11-13 Sugano, Ichikawa
City, Chiba 272-8513, Japan. ${ }^{3}$ International University of Health and Welfare Mita Hospital, 1-4-3 Mita, Minato-ku, Tokyo 180-8329, Japan. ${ }^{4}$ Division of Pharmacotherapeutics, Keio University School of Pharmacy, 1-5-30 Shibakoen, Minato-ku, Tokyo 105-8512, Japan.

Received: 25 June 2019 Accepted: 24 February 2020

Published online: 05 March 2020

\section{References}

1. Collaborators GDIIP. Global, regional, and national incidence, prevalence, and years lived with disability for 328 diseases and injuries for 195 countries, 1990-2016: a systematic analysis for the global burden of disease study 2016. Lancet. 2017:390(10100):1211-59.

2. Gines P, Quintero E, Arroyo V, Teres J, Bruguera M, Rimola A, et al. Compensated cirrhosis: natural history and prognostic factors. Hepatology. 1987;7(1):122-8.

3. Lucena Ml, Andrade RJ, Tognoni G, Hidalgo R, De La Cuesta FS. Spanish collaborative study group on therapeutic management in liver D. multicenter hospital study on prescribing patterns for prophylaxis and treatment of complications of cirrhosis. Eur J Clin Pharmacol. 2002;58(6): 435-40

4. Kyle UG, Bosaeus I, De Lorenzo AD, Deurenberg P, Elia M, Manuel Gomez J, et al. Bioelectrical impedance analysis-part II: utilization in clinical practice. Clin Nutr. 2004:23(6):1430-53.

5. Ceniccola GD, Castro MG, Piovacari SMF, Horie LM, Correa FG, Barrere APN, et al. Current technologies in body composition assessment: advantages and disadvantages. Nutrition. 2019;62:25-31.

6. Hara N, Iwasa M, Iwata K, Miyachi H, Tanaka H, Takeo M, et al. Value of the extracellular water ratio for assessment of cirrhotic patients with and without ascites. Hepatol Res. 2009;39(11):1072-9.

7. Davenport A, Argawal B, Wright G, Mantzoukis K, Dimitrova R, Davar J, et al. Can non-invasive measurements aid clinical assessment of volume in patients with cirrhosis? World J Hepatol. 2013;5(8):433-8.

8. Holland-Fischer $P$, Nielsen MF, Vilstrup $H$, Tonner-Nielsen D, Mengel A, Schmitz $\mathrm{O}$, et al. Insulin sensitivity and body composition in cirrhosis: changes after TIPS. Am J Physiol Gastrointest Liver Physiol. 2010;299(2): G486-93.

9. Hernaez R, Sola E, Moreau R, Gines P. Acute-on-chronic liver failure: an update. Gut. 2017:66(3):541-53.

10. European Association for the Study of the Liver. Electronic address eee, European Association for the Study of the L. EASL clinical practice guidelines for the management of patients with decompensated cirrhosis. J Hepatol. 2018;69(2):406-60.

11. Nomoto H, Satoh Y, Kamiyama M, Yabe K, Masumura M, Sakakibara A, et al. Mechanisms of diuresis for acute decompensated heart failure by Tolvaptan. Int Heart J. 2017:58(4):593-600.

12. Rhee $H$, Jang KS, Shin MJ, Lee JW, Kim IY, Song SH, et al. Use of multifrequency bioimpedance analysis in male patients with acute kidney injury who are undergoing continuous Veno-venous Hemodiafiltration. PLoS One. 2015:10(7):e0133199.

13. Molfino A, Amabile Ml, Ammann T, Farcomeni A, Lionetto L, Simmaco M, et al. The metabolite beta-aminoisobutyric acid and physical inactivity among hemodialysis patients. Nutrition. 2017;34:101-7.

14. Tabinor M, Elphick E, Dudson M, Kwok CS, Lambie M, Davies SJ. Bioimpedancedefined overhydration predicts survival in end stage kidney failure (ESKF): systematic review and subgroup meta-analysis. Sci Rep. 2018;8(1):4441.

15. Schrier RW, Gross P, Gheorghiade M, Berl T, Verbalis JG, Czerwiec FS, et al. Tolvaptan, a selective oral vasopressin V2-receptor antagonist, for hyponatremia. N Engl J Med. 2006:355(20):2099-112.

16. Berl T, Quittnat-Pelletier F, Verbalis JG, Schrier RW, Bichet DG, Ouyang J, et al. Oral tolvaptan is safe and effective in chronic hyponatremia. J Am Soc Nephrol. 2010;21(4):705-12.

17. Decaux G, Soupart A, Vassart G. Non-peptide arginine-vasopressin antagonists: the vaptans. Lancet. 2008;371(9624):1624-32.

18. Sakaida I, Kawazoe S, Kajimura K, Saito T, Okuse C, Takaguchi K, et al. Tolvaptan for improvement of hepatic edema: a phase 3, multicenter, randomized, double-blind, placebo-controlled trial. Hepatol Res. 2014;44(1): $73-82$.

19. Kogiso T, Tokushige K, Hashimoto E, Ikarashi Y, Kodama K, Taniai M, et al. Safety and efficacy of long-term tolvaptan therapy for decompensated liver cirrhosis. Hepatol Res. 2016;46(3):E194-200. 
20. Hiramine $Y$, Uto $H$, Imamura $Y$, Hiwaki $T$, Kure $T$, ljuin $S$, et al. Efficacy of vasopressin $\mathrm{V} 2$ receptor antagonist tolvaptan in treatment of hepatic edema. Hepatol Res. 2017;47(6):542-57.

21. Wang S, Zhang X, Han T, Xie W, Li Y, Ma H, et al. Tolvaptan treatment improves survival of cirrhotic patients with ascites and hyponatremia. BMC Gastroenterol. 2018;18(1):137.

22. Tahara T, Mori K, Mochizuki M, Ishiyama R, Noda M, Hoshi H, et al. Tolvaptan is effective in treating patients with refractory ascites due to cirrhosis. Biomed Rep. 2017;7(6):558-62.

23. Tajiri K, Tokimitsu Y, Ito H, Atarashi Y, Kawai K, Minemura M, et al. Survival benefit of Tolvaptan for refractory ascites in patients with advanced cirrhosis. Dig Dis. 2018;36(4):314-21.

24. Pose E, Sola E, Piano S, Gola E, Graupera I, Guevara M, et al. Limited efficacy of Tolvaptan in patients with cirrhosis and severe Hyponatremia: real-life experience. Am J Med. 2017;130(3):372-5.

25. Dahl E, Gluud LL, Kimer N, Krag A. Meta-analysis: the safety and efficacy of vaptans (tolvaptan, satavaptan and lixivaptan) in cirrhosis with ascites or hyponatraemia. Aliment Pharmacol Ther. 2012;36(7):619-26.

26. Goldsmith SR, Bart BA, Burnett J. Decongestive therapy and renal function in acute heart failure: time for a new approach? Circ Heart Fail. 2014;7(3): 531-5.

27. Arroyo V, Gines P, Gerbes AL, Dudley FJ, Gentilini P, Laffi G, et al. Definition and diagnostic criteria of refractory ascites and hepatorenal syndrome in cirrhosis. Int Ascites Club Hepatol. 1996;23(1):164-76.

28. Kim WR, Biggins SW, Kremers WK, Wiesner RH, Kamath PS, Benson JT, et al. Hyponatremia and mortality among patients on the liver-transplant waiting list. N Engl J Med. 2008;359(10):1018-26.

29. Fukui H, Saito H, Ueno Y, Uto H, Obara K, Sakaida I, et al. Evidence-based clinical practice guidelines for liver cirrhosis 2015. J Gastroenterol. 2016; 51(7):629-50.

30. Miyaaki H, Nakamura Y, Ichikawa T, Taura N, Miuma S, Shibata H, et al. Predictive value of the efficacy of tolvaptan in liver cirrhosis patients using free water clearance. Biomed Rep. 2015;3(6):884-6.

31. Maioli M, Toso A, Leoncini M, Musilli N, Bellandi F, Rosner MH, et al. Preprocedural bioimpedance vectorial analysis of fluid status and prediction of contrast-induced acute kidney injury. J Am Coll Cardiol. 2014;63(14):138794.

32. Kyle UG, Bosaeus I, De Lorenzo AD, Deurenberg P, Elia M, Gomez JM, et al. Bioelectrical impedance analysis--part I: review of principles and methods. Clin Nutr. 2004:23(5):1226-43.

33. Mosteller RD. Simplified calculation of body-surface area. N Engl J Med. 1987;317(17):1098.

34. Masuda T, Murakami T, Igarashi Y, Okabe K, Kobayashi T, Takeda SI, et al. Dual impact of Tolvaptan on intracellular and extracellular water in chronic kidney disease patients with fluid retention. Intern Med. 2016;55(19):275964.

35. DeLong ER, DeLong DM, Clarke-Pearson DL. Comparing the areas under two or more correlated receiver operating characteristic curves: a nonparametric approach. Biometrics. 1988;44(3):837-45.

36. Angeli $P$, Wong $F$, Watson $H$, Gines $P$, Investigators $C$. Hyponatremia in cirrhosis: results of a patient population survey. Hepatology. 2006;44(6): $1535-42$.

37. Selberg $\mathrm{O}$, Selberg D. Norms and correlates of bioimpedance phase angle in healthy human subjects, hospitalized patients, and patients with liver cirrhosis. Eur J Appl Physiol. 2002;86(6):509-16.

38. Nagayama I, Masuda T, Nakagawa S, Murakami T, Ohara K, Matsuoka R, et al. Different effects on fluid distribution between Tolvaptan and furosemide in a liver cirrhosis patient with chronic kidney disease. Intern Med. 2019;58(11): 1587-91.

39. Dantzler WH, Layton AT, Layton HE, Pannabecker TL. Urine-concentrating mechanism in the inner medulla: function of the thin limbs of the loops of Henle. Clin J Am Soc Nephrol. 2014;9(10):1781-9.

40. Kawaratani H, Fukui H, Moriya K, Noguchi R, Namisaki T, Uejima M, et al. Predictive parameter of tolvaptan effectiveness in cirrhotic ascites. Hepatol Res. 2017;47(9):854-61

41. Sakaida I, Terai S, Nakajima K, Shibasaki Y, Tachikawa S, Tsubouchi H. Predictive factors of the pharmacological action of tolvaptan in patients with liver cirrhosis: a post hoc analysis. J Gastroenterol. 2017:52(2):229-36.

42. Hiramine $Y$, Uto H, Mawatari S, Kanmura S, Imamura $Y$, Hiwaki T, et al. Effect of tolvaptan on the prognosis of patients with hepatic ascites. Hepatol Res. 2019;49(7):765-77.
43. Sone M, Albrecht GJ, Dorge A, Thurau K, Beck FX. Osmotic adaptation of renal medullary cells during transition from chronic diuresis to antidiuresis. Am J Phys. 1993;264(4 Pt 2):F722-9.

44. Nakanishi $T$, Yamauchi $A$, Nakahama $H$, Yamamura $Y$, Yamada $Y$, Orita $Y$, et al. Organic osmolytes in rat renal inner medulla are modulated by vasopressin V1 and/or V2 antagonists. Am J Phys. 1994;267(1 Pt 2):F146-52.

45. Marra M, Sammarco R, De Lorenzo A, lellamo F, Siervo M, Pietrobelli A, et al. Assessment of body composition in health and disease using bioelectrical impedance analysis (BIA) and dual energy X-ray absorptiometry (DXA): a critical overview. Contrast Media Mol Imaging. 2019;2019:3548284.

46. Fernandes SA, de Mattos AA, Tovo CV, Marroni CA. Nutritional evaluation in cirrhosis: emphasis on the phase angle. World J Hepatol. 2016;8(29):120511.

\section{Publisher's Note}

Springer Nature remains neutral with regard to jurisdictional claims in published maps and institutional affiliations.
Ready to submit your research? Choose BMC and benefit from:

- fast, convenient online submission

- thorough peer review by experienced researchers in your field

- rapid publication on acceptance

- support for research data, including large and complex data types

- gold Open Access which fosters wider collaboration and increased citations

- maximum visibility for your research: over $100 \mathrm{M}$ website views per year

At BMC, research is always in progress.

Learn more biomedcentral.com/submissions 